\title{
Quantum-chemical study of carbon nanotubes interaction with contaminants of petroleum, oil and lubricants
}

\author{
I. Arkharova, I. Zaporotskova \\ Volgograd State University, Volgograd, Russia \\ arkharova_irina@mail.ru, irinazaporotskova@gmail.com
}

PACS 61.46.Fq, 61.48.De, 62.23.Pq

DOI 10.17586/2220-8054-2016-7-1-253-259

The article presents the results from the study of carbon nanotube (CNT) interaction with the main products generated in the process of oil "aging", in particular with a molecule of sulfurous acid, hydroxyl group, ferrous and aluminium oxides. The purpose of the paper is to prove the possibility of oxygen atom adsorption on the outside face of CNT.

Keywords: petroleum, oil and lubricants, nanomaterials, carbon nanotubes, quantum-chemical calculations, DFT.

Received: 20 November 2015

\section{Introduction}

Oil changes its physico-chemical and functional properties during long-term service (i.e. it "ages"); and its quality parameters reach their limits with respect to the norms [1]. When oil decomposes as a result of oxidation or under the influence of other factors, its acidity increases. Acids are the major products of the aging process for oil. These acidic products can cause metal corrosion, and in order to neutralize generated acids alkali additives are required, therefore negatively affecting the dispersive properties and detergency of oil, as well as its operational life. Active sulfur compounds that penetrate oil after combustion of fuel with high sulfur content frequently cause oil aging [2]. Inorganic contaminants come in contact with oil as a result of mechanical friction of rubbing engine parts and consist mainly of quartz, feldspar, metal oxides and metal particles $[3,4]$. The detergents, which are the part of engine oil, are organometallic compounds. When oil enters the combustion chamber and is burned, ash particles are formed, consisting of metal oxides and salts belonging to the additives. Ash particles clog the pores of the ash filter, and do not allow it to regenerate completely. For this reason, the search for a means to remove these products of oil aging is relevant and of practical use.

One of the ways of cleaning and removing the undesirable oil by-products which are formed is the introduction of various active additives. It is assumed that carbon nanotubes $[5,6]$ can be used as an admixture that will significantly improve the properties and operational characteristics of lubricating materials. The essential peculiarity of carbon nanotubes arises as a result of their unique sorption characteristics [7-9]. Due to the fact that a nanotube is a surface structure, its weight is enclosed in surfaces of its layers. This defines an abnormally high specific surface area of tubules, and that, in turn, determines their electro-chemical and sorption characteristics [10]. We assume that harmful impurity (acids, oxides of metals, etc.) can be adsorbed onto the nanotubes' surfaces and subsequently removed from the oil via filtration.

In order to prove the feasibility this process, it is necessary to execute theoretical calculations for the adsorptive interaction of a carbon nanotube and some metal oxides resulting from the degradation of oil and its additives. As a result, different-valence oxides of iron and aluminum were chosen, and interaction process between carbon nanotube and a molecule 
of sulfurous acid, hydroxyl group were modeled. The top-priority objective in this case was the calculation of the optimal geometrical structure for a nano-sized molecular cluster, which is clearly considered an important quantum chemistry issue [11-14]. Due to complexity of investigated molecular systems, density functional theory (DFT) has been used in this study to calculate the structure for the molecular cluster [15].

\section{Quantum-chemical study of carbon nanotubes interaction with contaminants in petroleum, oil and lubricants}

The paper presents the results of a study for modeling the interaction of a type $(6,0)$ carbon nanotube with several base products generated during oil aging, such as a molecule of sulfurous acid, a hydroxyl group, iron and aluminum oxides. The molecular cluster of a nanotube containing 96 atoms of carbon is considered. The clusters' boundaries were closed with pseudo-atoms; in this case, they were hydrogen atoms.

Processes of adsorptive interaction of the chosen type for single-layer nanotubes with a hydroxyl group, with a molecule of sulfurous acid $\mathrm{H}_{2} \mathrm{SO}_{3}$, with structural units (elemental fragments) of iron oxides ( $\mathrm{FeO} \& \mathrm{Fe}_{2} \mathrm{O}_{3}$ ), with structural units (elemental fragments) of aluminium oxide $\left(\mathrm{Al}_{2} \mathrm{O}_{3}\right)$ were also studied. Process was simulated by means of a stepwise approximation (one step equals $0.1 \AA$ ) towards the surface of a carbon tubule, located approximately in the middle of the cluster. Perpendicular connection to the surface of a nanotube with use of active center of a structural unit - an oxygen atom was considered. The oxygen atom, due to the presence of a double bond, can provide adsorptive interaction with the nanotube. Examples of a adsorption complexes "cluster of nanotubulene $(6,0)$ - molecules (structural units) of harmful components of fuel" are presented in Fig. 1.

Based on the results of theoretical calculations, the potential interaction energy profile for a CNT with a hydroxyl group has been constructed. Analysis of this profile allows one to define the main adsorptive characteristics of this process, which are presented in Table 1.

TABLE 1. General adsorption characteristics of interaction of a single-layer $(6,0)$

CNT with chosen contaminants

\begin{tabular}{|c|c|c|}
\hline Contaminant & $\begin{array}{c}\text { Adsorption distance } \\
\text { r, } \AA\end{array}$ & $\begin{array}{c}\text { Adsorption energy } \\
\mathrm{E}_{\text {ads }}, \mathrm{eV}\end{array}$ \\
\hline $\mathrm{FeO}$ & 3.1 & -8.43 \\
\hline $\mathrm{Fe}_{2} \mathrm{O}_{3}$ & 2.0 & -6.66 \\
\hline $\mathrm{OH}$ & 2.4 & -0.8 \\
\hline $\mathrm{H}_{2} \mathrm{SO}_{3}$ & 2.6 & -0.51 \\
\hline $\mathrm{Al}_{2} \mathrm{O}_{3}$ & 3.1 & -0.43 \\
\hline
\end{tabular}

It is stated that hydroxyl group is adsorbed onto the surface of a $(6,0) \mathrm{CNT}$, which is illustrated by the presence of the minimum on the interaction curve (Fig. 2). The distance between the carbon atom of the tube surface and oxygen atom (adsorption distance) amounts to $r=2.4 \AA$; the adsorption energy in this case is $E_{a d s}=-0.8 \mathrm{eV}$. The correlation between our obtained results and those from a study on the adsorption of water molecules onto graphene [16] should be noted. The large value of adsorption energy, in our case in comparison with the values, which are presented in [16], due to the curvature of the nanotube surface, contributing to more active adsorption, and the presence of free communication in the hydroxyl group, which isn't present in the $\mathrm{H}_{2} \mathrm{O}$ molecule. 


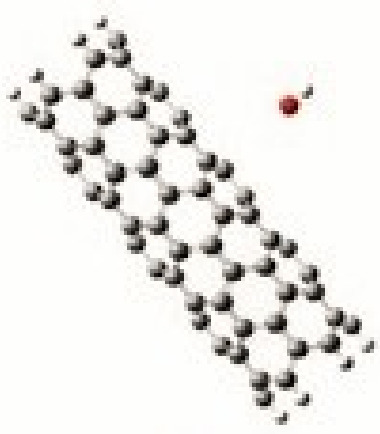

a)

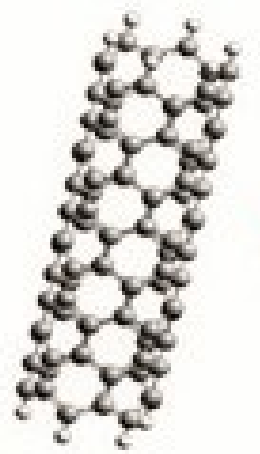

b)

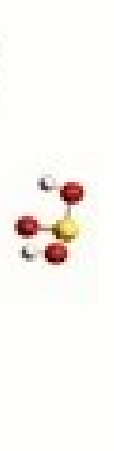

0

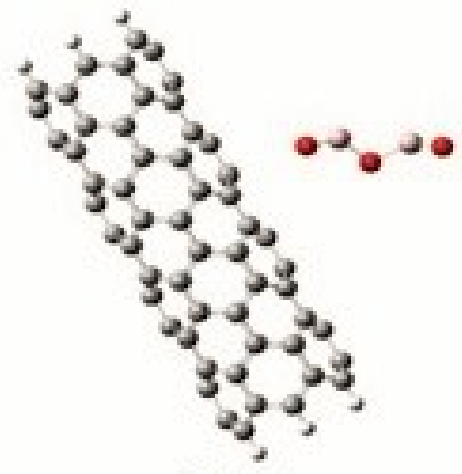

c)

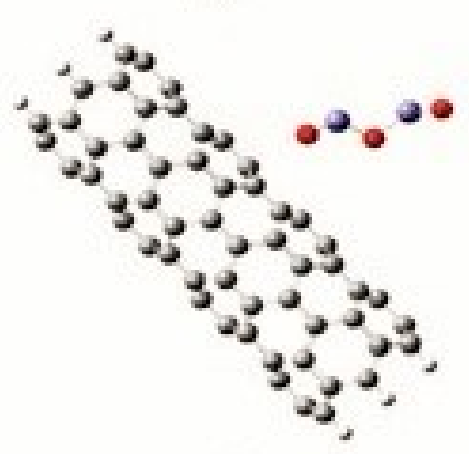

d)

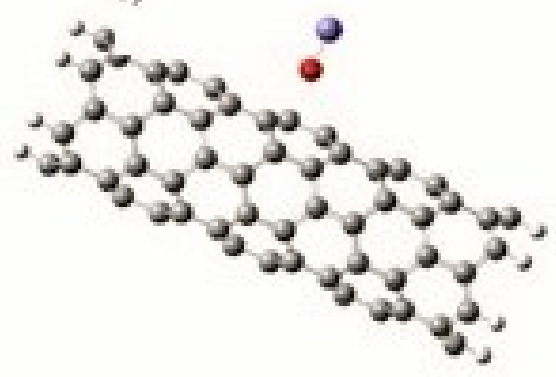

e)

FIG. 1. Model of a single-layer $(6,0)$ CNT molecular cluster interacting with: a) hydroxyl group; b) molecule of sulfurous acid; c) fragment of aluminium oxide $\mathrm{Al}_{2} \mathrm{O}_{3} ;$ d), e) fragments of aliovalent iron oxides: $\mathrm{Fe}_{2} \mathrm{O}_{3} ; \mathrm{FeO}$, correspondingly

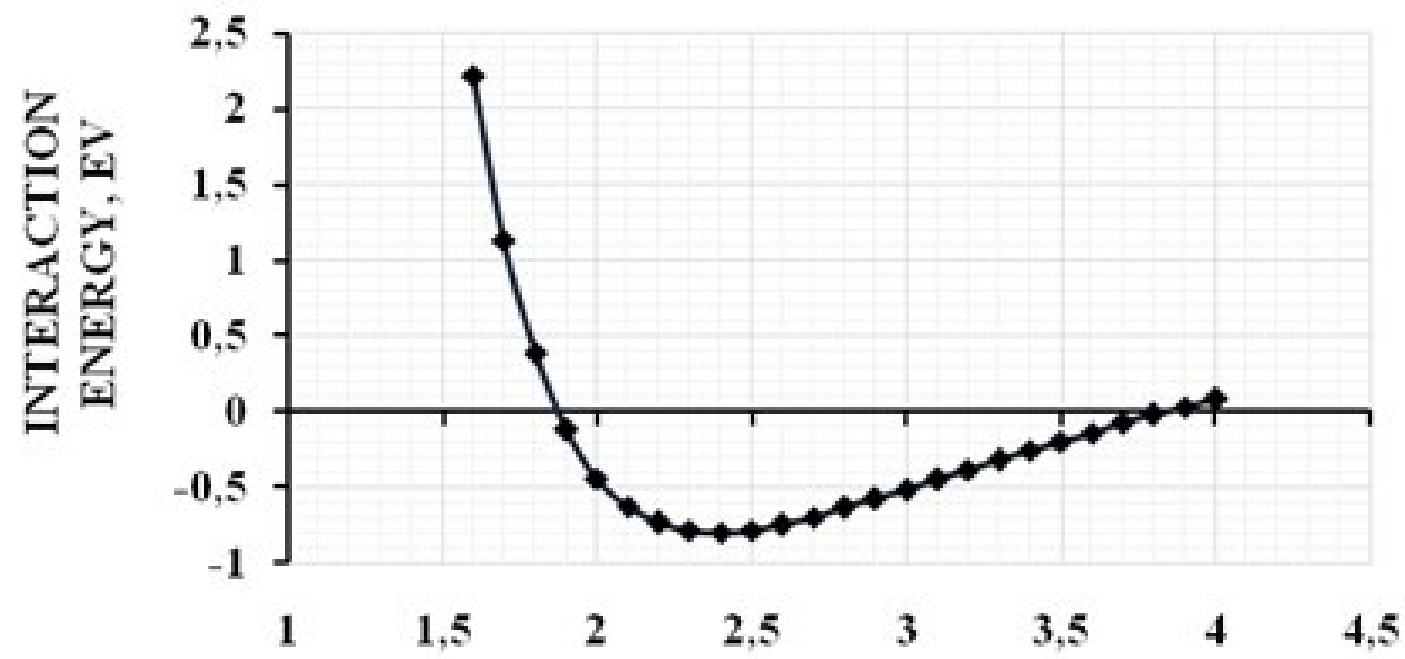

DISTANCE, $\AA$

FIG. 2. Surface profile for the potential energy of adsorptive interaction between a $(6,0) \mathrm{CNT}$ and a hydroxyl group 
As a result of theoretical calculations, the potential interaction energy profile of nanotubule with chosen molecule of sulfurous acid was constructed (Fig. 3). Analysis of this profile allowed definition of the main adsorptive characteristics of the process. The presence of a minimum on the curve indicates the implementation of the adsorption interaction between the $\mathrm{H}_{2} \mathrm{SO}_{3}$ molecule and the surface of the CNT.

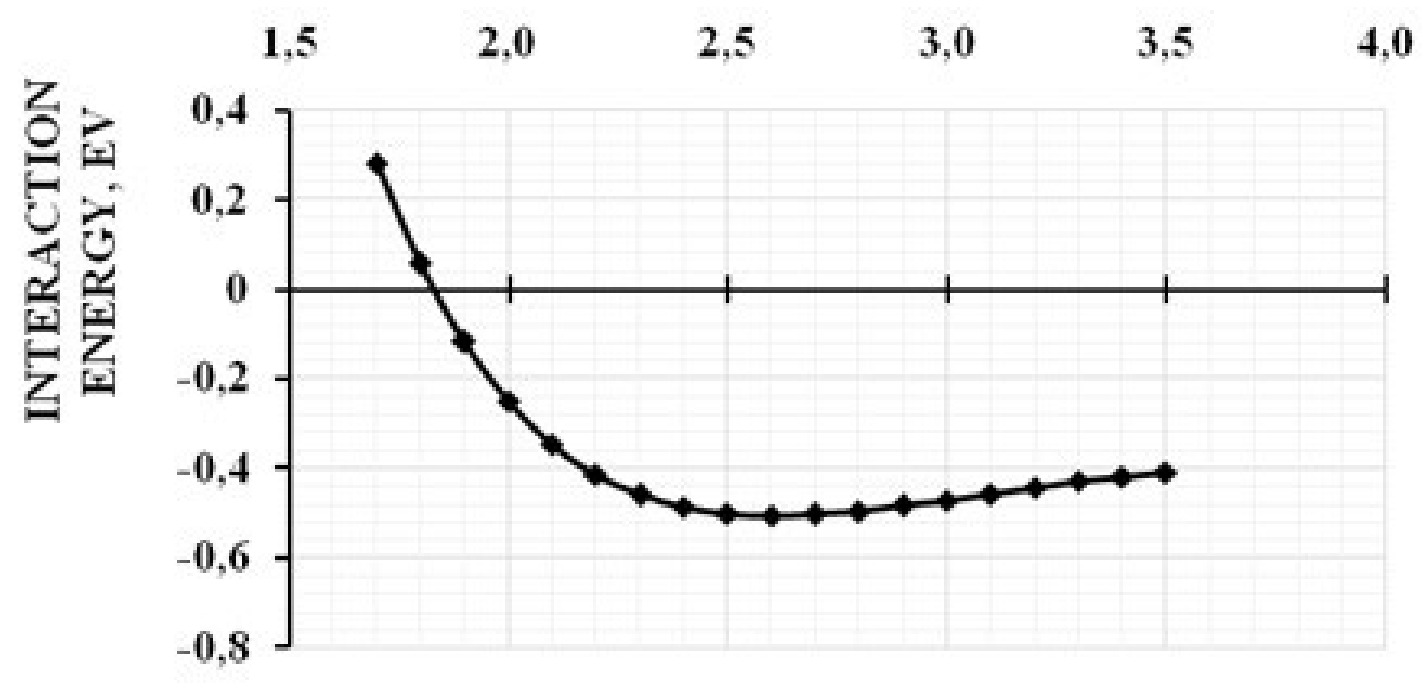

DISTANCE, $\AA$

FIG. 3. Surface profile of potential energy of adsorptive interaction between a nanotube $(6,0)$ and sulfurous acid

The adsorption distance was $r=2.6 \AA$, and the adsorption energy in this case was $E_{a d s}=-0.51 \mathrm{eV}$. As a result of theoretical calculations, the potential interaction energy profiles of nanotubules with elemental fragments of iron oxides acid were constructed. It is stated that fragment $\mathrm{Fe}_{2} \mathrm{O}_{3}$ is adsorbed on the surface of a $(6,0)$ CNT. The adsorption distance was $r=2.0 \AA$, while the adsorption energy was $E_{a d s}=-6.66 \mathrm{eV}$ (Fig. 4).

It is stated that the $\mathrm{FeO}$ fragment is adsorbed onto the surface of a $(6,0) \mathrm{CNT}$. The adsorption distance was $r=2.1 \AA$, and the adsorption energy was $E_{a d s}=-8.43 \mathrm{eV}$ (Fig. 5).

Also the interaction process of a $(6,0) \mathrm{CNT}$ with an aluminum oxide fragment was investigated. A surface interaction potential energy profile for a CNT with an aluminum oxide fragment was developed (Fig. 6) using a step-by-step approximation of $\mathrm{Al}_{2} \mathrm{O}_{3}$ approaching to the selected carbon atom on the CNT surface. Analysis of this profile allowed us to define the main adsorptive characteristics of the process. The adsorption distance was $r=3.1 \AA$, and the adsorption energy in this case was $\mathrm{E}_{a d s}=-0.43 \mathrm{eV}$.

A summary is shown in Table 1 for the general adsorption characteristics for the interactions between a single-layer $(6,0)$ CNT with contaminants that would be expected to be generated during the normal operation of an oil-lubricated internal combustion engine. The comparison of these adsorption energy values shows that the adsorptive process is most active with ferrous oxide, $\mathrm{FeO}$. This can be explained by the structure of elementary structural units, namely, higher activity of the oxygen atom in the structure. However, other harmful components resulting from the aging of fuel, are also adsorbed onto the CNT surface. Thus, it can 


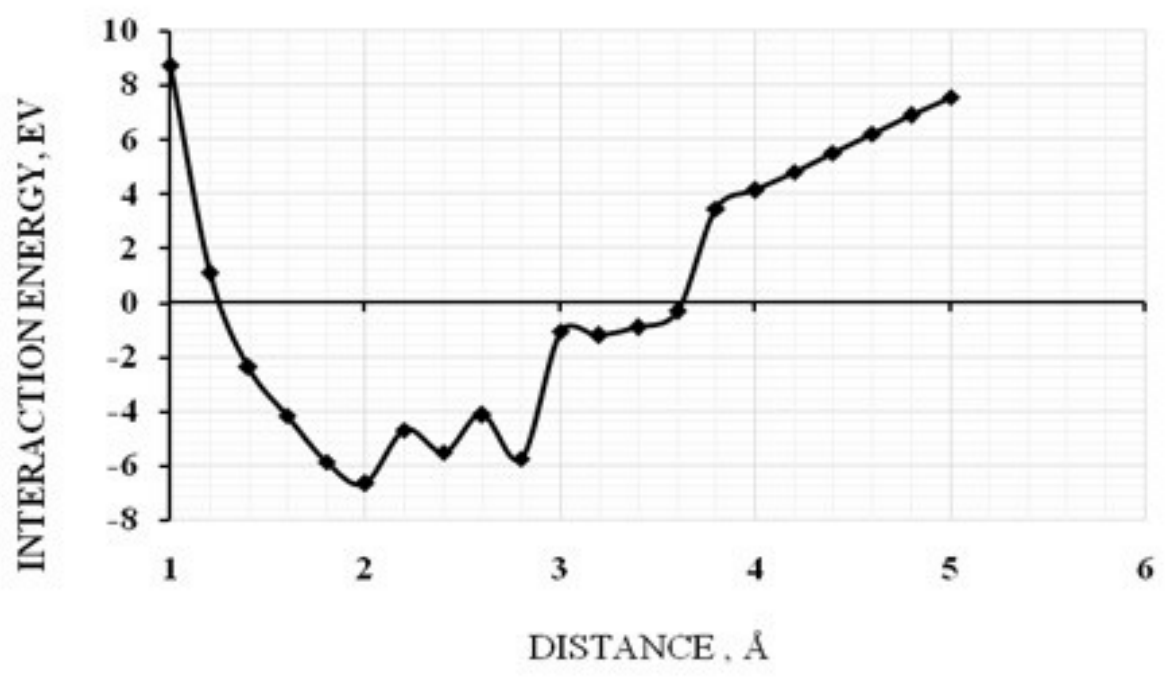

FIG. 4. Surface profile of potential energy for the adsorptive interaction between a $(6,0) \mathrm{CNT}$ and $\mathrm{Fe}_{2} \mathrm{O}_{3}$ fragment

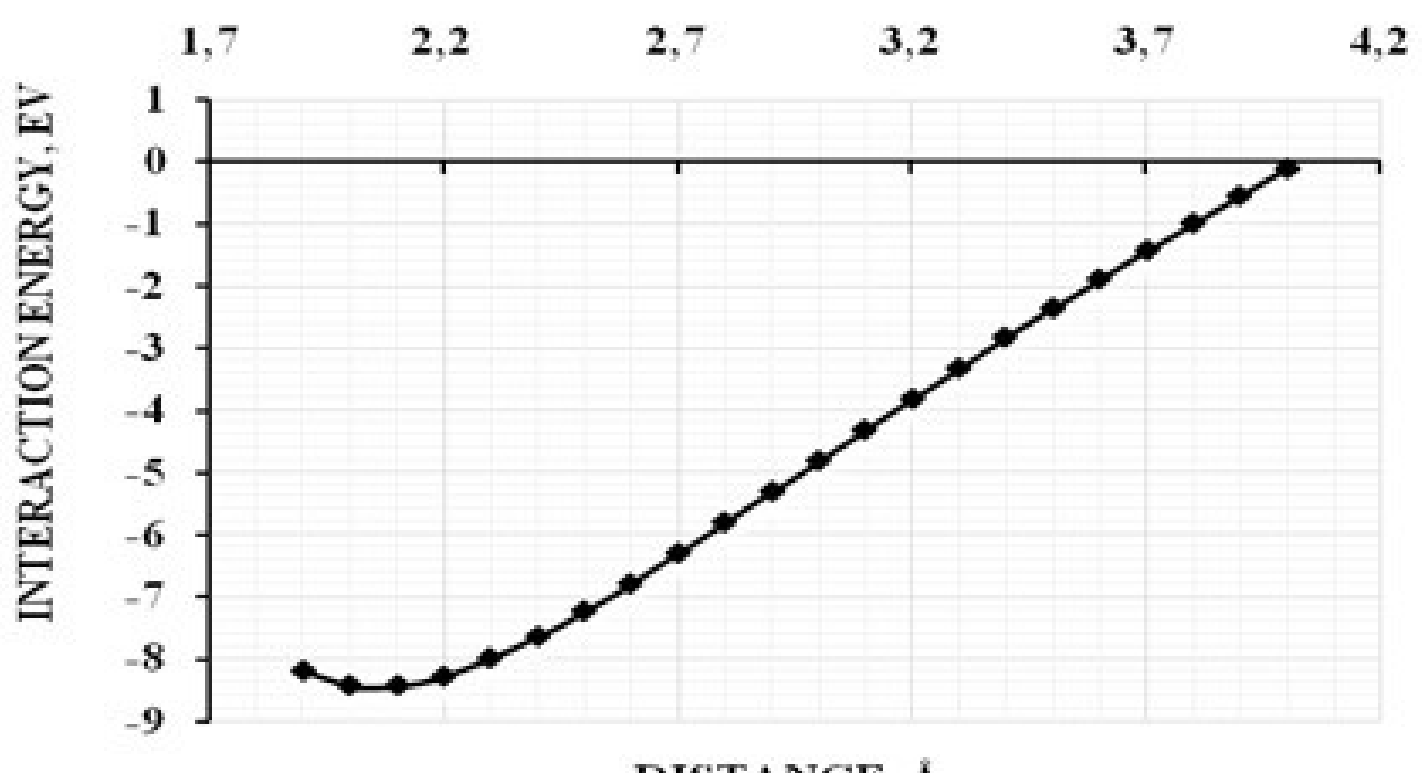

FIG. 5. Surface profile of potential energy of adsorptive interaction between a $(6,0) \mathrm{CNT}$ and a FeO fragment 


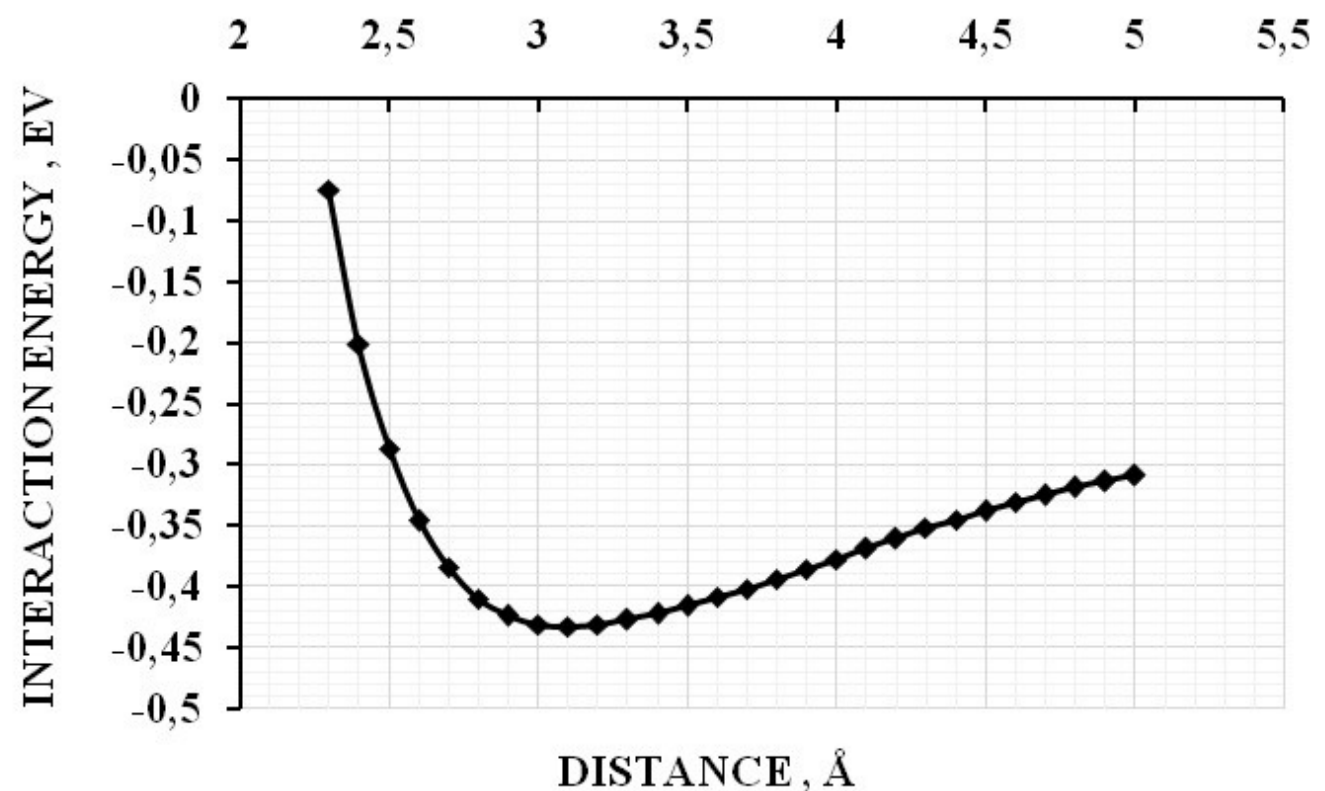

FIG. 6. Surface potential energy profile for the adsorptive interaction between a $(6,0) \mathrm{CNT}$ and an $\mathrm{Al}_{2} \mathrm{O}_{3}$ fragment

be argued that it is possible to use CNTs as active additive in both fuels and lubricants, the main mechanism by which this positive effect on oil is exerted, is the adsorption of harmful components onto the CNT surface.

\section{Summary and conclusions}

The theoretical quantum-chemical study of the adsorptive interaction of CNTs with a molecule of sulfurous acid, hydroxyl group, ferrous oxides and aluminum oxide proves the possibility CNTs interacting with the contaminants generated during the operation of an internal combustion engine using oil as a lubricant. Analysis of the results shows that the adsorptive process is most active with ferrous oxides. Therefore, the hierarchy for the petroleum oil and lubricant (POL) contaminants chosen with respect to CNT activity can be presented as follows: $\mathrm{FeO}, \mathrm{Fe}_{2} \mathrm{O}_{3}, \mathrm{OH}, \mathrm{H}_{2} \mathrm{SO}_{3}, \mathrm{Al}_{2} \mathrm{O}_{3}$. The main mechanism by which the CNTs exert a positive effect upon the lubricant during its degradation via normal operation, is the adsorption of harmful components onto the surface of the CNTs.

\section{References}

[1] Bujanovskij I.A., Fuks I.G., Shabalina T.N. Boundary lubrication: stages of tribology development. Nefti gas, Moscow, 2002.

[2] Badisova K.M., Berstad J.A., Bogdanov S.K., Shkolnikov V.M., Anisimov I.G., Batov S.A. Fuels, lubricating materials, technical liquids. Variety and application: manual. Publishing center "Tekhinform", Moscow, 1999.

[3] Ventsel E.S., Zhalkin S.G., Danko N.I. Improvement of quality and increase of service life of petroleum oils. Ukrainian State University of Railway Transport, Kharkov, 2003, 168 pp.

[4] Grigoriev M.A. Quality of engine oil and reliability of engines. Publishing house of standards, Moscow, 1981, $232 \mathrm{pp}$. 
[5] Ljuty M., Kostyukovich G., Kravchenko V., Struk V., Ovchinnikov E. Tribo-technical characteristics of lubricating materials modified with nanodesperse fillers. Nanostructural materials. Abstr. 2-nd scitech. seminar 24-25 October 2002, IMET RAN, Belorussia - Russia, 2002.

[6] Lubricating oil composition for friction reduction that includes nanoporous particles: pat. Russian Federation: B82B C10M C10N / Lee Hyeung Jin; Cho Yong Rae; patent applicant and holder SK LubricantsCo., Ltd. 2012145479/04; applic. 16.03.11; publ. 10.04.14, Journal. 10.

[7] Eleckij A.V. Sorption properties of carbon nanostructures. Physics Uspekhi, 2004, 47(11), P. 1119-1154.

[8] Harris P. Carbon Nanotubes and Related Structures. New Materials for the Twenty-first Century. Tekhnosfera, Moscow, 2003, 336 p.

[9] Djachkov P.N. Carbon nanotubes: morphology, properties, applications. Binom, Moscow, 2010.

[10] Zaporotskova I.V. Carbon and non-carbon nanomaterials and composite structures on its base: morphology and electron properties. Volgograd State University Press, Volgograd, 2009, 490 p.

[11] Kotliar G., Savrasov S.Y., Haule K., Oudovenko V.S., Parcollet O., Marianetti C.A. Electronic structure calculations with dynamical mean-field theory. Rev. Mod. Phys., 2006, 78(3), P. 865-951.

[12] Wang Z., Gao F., Li N., Qu N., Gou H., Hao X. Density functional theory study of hexagonal carbon phases. J. Phys.: Condens. Matter, 2009, 21, P. 235401-235406.

[13] Bajsupova E., Aminova R.M. Modelling of molecular nanosize clusters with quantum chemistry methods. Butlerov's messages, 2009, P. 10-22.

[14] Ignatov S.K. Quantum-chemical modelling of molecular structure, physico-chemical properties and reactive capacity. Novgorod State University Press, Nizhni Novgorod, 2006, 82 p.

[15] Reich S., Thomsen C., Maultzsch J. Carbon nanotubes. Basic concepts and physical properties. Wiley, VCH Verlag, Berlin, 2003.

[16] Rangel Cortes E., Magaña Soí L.F., Arellano J.S. Interaction of a water molecule with a graphene layer. Revista Mexicana de Física, 2013, 59(1), P. 118-125. 